DOI: https://doi.org/10.24867/11FA21Zvezdin

\title{
IDEJNO REŠENJE STAMBENOG BLOKA JEDNOPORODIČNOG STANOVANJA PO PRINCIPIMA ODRŽIVE ARHITEKTURE - napredne tehnike u procesu projektovanja
}

\section{CONCEPTUAL DESIGN OF A SINGLE-FAMILY HOUSING BLOCK ACCORDING TO THE PRINCIPLES OF SUSTAINABLE ARCHITECTURE - advanced techniques in the design process}

\section{Nina Zvezdin, Fakultet tehničkih nauka, Novi Sad}

\section{Oblast - SAVREMENE TEORIJE I TEHNOLOGIJE U ARHITEKTURI}

Kratak sadržaj - Poslednjih godina, koncept održivosti je postao zajednička tema brojnih disciplina. Budući da je građevinska industrija jedna od glavnih uzročnika emisija ugljen-dioksida, uništavanja nezamenljivih resursa $i$ klimatskih promena, primena zelenog načina gradnje je od vitalne važnosti. Cilj ovog rada je da se pruži uvid u ozbiljnost navedenog problema, kao $i$ da predstavi primere $i$ opcije raznih načina održivog $i$ energetski efikasnog dizajna. Kroz istraživanje $i$ studiju slučaja, razmatraju se savremene metode i brojna pomagala koja imamo danas zahvaljujuci enormnom napretku tehnologije. Rad je završen projektom idejnog rešenja stambenog bloka jednoporodičnog stanovanja uz upotrebu algoritma po uzoru na Ćelijski automat, kao $i$ Revit Insight tehnologiju.

Ključne reči: Arhitektonsko projektovanje, održiva arhitektura, ćelijski automat, jednoporodično stanovanje

Abstract - In recent years, the concept of sustainability has become the common theme of numerous disciplines. Due to the building industry being one of the main causers of our carbon footprint, destruction of irreplaceable recourses and climate change, implementing the green way of building is of vital importance. The aim is to provide insight of the seriousness of said issues, as well as examples and options of different ways of sustainable and energy efficient design. Through research and case study, modern methods and numerous aids we have today are being considered. The thesis concludes with a conceptual design of a single-family housing block, with the application of advanced technologies in the design process.

Keywords: Architectural design, sustainable architecture, cellular automata, single-family housing

\section{UVOD}

U poslednjih pola veka čovečanstvo se suočava sa mogućnošću samouništenja. Zahvaljujući tome održivost je postala bitna tema mnogih disciplina. Nauka održivosti se bavi pronalaženjem načina i tehnologija potrebnih za očuvanje resursa koji omogućavaju opstanak svih živih

\section{NAPOMENA:}

Ovaj rad proistekao je iz master rada čiji mentor je bio doc. dr Dejan Ecet. bića, kao i same planete. Kao jedan od najvećih uzročnika emisija ugljen-dioksida i uništavanja nezamenljivih resursa, građevinska industrija mora doživeti značajnu transformaciju. Da bi se negativni efekti ograničili i zamenili ekološki prihvatljivim načinom izgradnje, sistemi zelene gradnje se moraju uvesti, razumeti i praktikovati [1].

Zahvaljujući enormnom napretku tehnologije, u današnje vreme imamo na raspolaganju brojna pomagala koja nam olakšavaju proces projektovanja.

Cilj ovog istraživanja jeste da se pruži uvid u ozbiljnost navedenog problema i prikažu mogući načini upotrebe savremene tehnologije u procesu projektovanja.

\section{METODOLOGIJA}

Vrši se istraživanje i izučavanje naprednih tehnika koje se mogu koristiti u procesu projektovanja u svrhu olakšanja i bolje optimizacije projekta.

\subsection{Primena naprednih tehnika u procesu projektovanja}

\subsubsection{Aktuelni softveri}

Zahvaljujući napretku tehnologije, na tržištu se nalaze brojni programi koji služe kao alati za simulaciju analize građevinskih performansi. Upotrebom odgovarajućih softvera možemo odrediti značajne činioce u ranim fazama projektovanja. Mogućnost predviđanja performansi objekta daje nam najveće šanse za optimizaciju projekta, kao i sticanje u odluke koje će imati značajan uticaj na njegov ugljenični otisak.

Softveri poput Energy Plus, OpenStudio i brojnih drugih pružaju mogućnost poređenja i povratne informacije već u konceptualnim fazama dizajna. U kasnijim fazama procesa projektovanja, srazmerno sa sve definisanijim planom objekta, tačnost predikcija postaje sve veća.

\subsubsection{Revit Insight tehnologija}

Revit Insight omogućava projektovanje energetski efikasnijih objekata pomoću naprednih simulacionih motora i podataka o analizi performansi integrisanih $\mathrm{u}$ Revit. Insight služi za analizu različitih performansi projektovanih objekata kako u razrađenoj formi, tako i u ranim fazama projekta. $\mathrm{Na}$ osnovu volumena, položaja, materijalizacije, otvora i drugih parametara, ovaj plug-in određuje grubu potrošnju energije uz predloge i mogućnost korigovanja faktora koji utiču na objekat. 


\subsubsection{Primena algoritma u projektovanju}

Napredak tehnologije doprinosi sve većoj upotrebi računara i veštačkoj inteligenciji - sve veći deo posla radi se automatski, odnosno zadavanjem komande mašini koja sama odradi posao. Decenijama, nakon mnogih uspešnih pokušaja, brojne kompanije uspevaju da iskoriste moć algoritamskog planiranja prostora. Određivanjem parametara, pravljenjem kodova i programa, moguće je odrediti oblik objekta, ili čak odrediti određeni obrazac osnove, preseka, parternog uređenja, itd. [2].

\section{ISTRAŽIVANJE - TEORIJSKA PRIMENA ĆELIJSKOG AUTOMATA U PROCESU PROJEKTOVANJA}

Ćelijski automat (Cellular Automaton) je diskretni model koji se proučava u sklopu oblasti teorija informatike, matematike, fizike, složenog adaptivnog sistema, teorijske biologije i mikrostrukture modelinga, slika 1. Koncept ćelijskog automata otkrili su Stanislaw Ulam i John von Neumann četrdesetih godina 20 . veka. On se sastoji od pravilne mreže ćelija od kojih je svaka u jednom od ograničenih stanja - uključeno (1) i isključeno (0). Mreža može biti bilo kojih dimenzija, s tim da je broj tih dimenzija ograničen, odnosno nije beskonačan. Za svaku ćeliju, niz ćelija koji se naziva njenim susedstvom, definisan je u odnosu na pomenutu ćeliju. Početno stanje (vreme $\mathrm{t}=0$ ) određuje se biranjem stanja za svaku od ćelija. Nova generacija se stvara $(\mathrm{f}=\mathrm{t}+1)$ prema određenom i nepromenljivom pravilu koje određuje novo stanje svake od ćelija, zavisno od trenutnog stanja ćelije i stanja ćelija u njenom susedstvu [3].

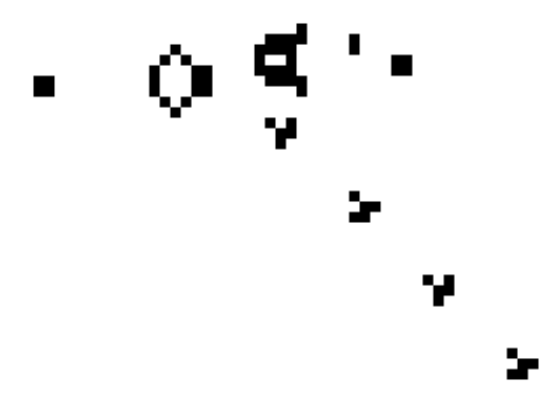

Slika 1. Ćelijski automat-Game of Life [3]

\subsection{Game of Green projektovanja}

Pri radu za predmet Optimizacione i upravljačke tehnologije $\mathrm{u}$ arhitektonskom projektovanju vrši se istraživanje o teorijskoj primeni algoritma pri određivanju zelenog prostora na parceli. Prvobitna ideja projekta bila je da se napravi algoritam po uzoru na Game of Life, koji će određivati izgrađene i neizgrađene površine, tako da se iskoristi maksimalna površina parcele/kompleksa.

$\mathrm{Na}$ osnovu definisanih uslova - dimenzije rastera, uslovi za izgradnju $(0>1)$, uslovi za rušenje $(1>0)$ - algoritam će određivati varijaciju izgrađene, odnosno, neizgrađene površine na najoptimalniji način. Navedeni uslovi se mogu menjati u zavisnosti od potreba projekta [4].

\subsection{Umnožavanje zelenih površina}

Daljim razrađivanjem projekta, uvodi se dodatna jedinica ( 2 - zelena površina), kao i nova dimenzija. Uvodi se

opcija određivanja višespratnih objekata/kompleksa, na osnovu uslova prethodnih etaža, slika 2.

Određuju se dimenzije rastera, odnosno parcele.

0 1 2 početno stanje - slobodan, neizgrađen prostor

izgrađen prostor (popločanje, objekat)

zelene površine (krovne bašte, terase i drugi oblici zelenih prostora)

Odnosi između ćelija - gore, dole, levo desno. Ako postoji 0 (0 prelazi u 1); ako su gore, dole, levo ili desno 1 u 7 ili više slučaja ( 0 prelazi u 2 ); ako su gore, dole, levo ili desno 1 (1 prelazi u 2).

Na mesto 1 prethodne etaže 0 prelazi u 1 ; na mesto 2 prethodne etaže 0 prelazi u 2 .

1 ne može biti iznad 2 na narednom spratu, osim ako pored 2 na prethodnom spratu nije 0.2 može biti iznad 1 na sledećem spratu [4].
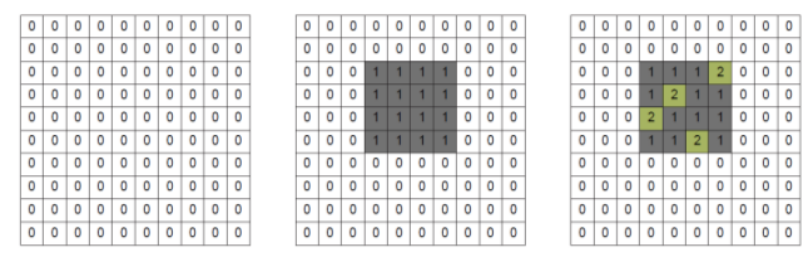

Slika 2. Umnožavanje zelenih površina na parceli [4]

\section{IDEJNO REŠENJE STAMBENOG BLOKA JEDNOPORODIČNOG STANOVANJA}

Projektovanje stambenog bloka jednoporodičnog stanovanja podeljeno je na četiri faze: 1 . određivanje veličine i gustine stambenog bloka/parcele primenom algoritma, 2 . energetska analiza dobijenih blokova, 3. usvajanje dispozicije stambenih jedinica i finalne analize bloka i 4 . razrada usvojene dispozicije.

\subsection{Primena algoritma za pronalazak paterna bloka}

Prvi korak ove faze jeste definisanje jedne stambene jedinice, odnosno minimalnog pripadajućeg prostora. Usvojeni gabarit stambene jedinice su dimenzije $6 \mathrm{~m} x$ $10.2 \mathrm{~m}$, odnosno dimenzije $12 \mathrm{~m} \times 10.2 \mathrm{~m}$ (10x10, radi održavanja pravilnosti rastera), što čini ukupan potreban prostor parcele, odnosno jedne jedinice u rasteru, slika 3 .

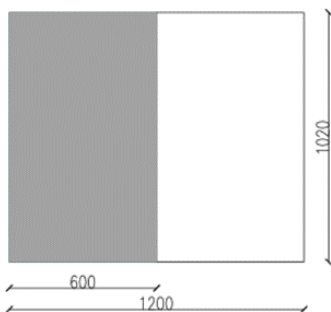

Slika 3. Stambena jedinica sa parcelom (ćelija rastera)

Drugi korak ove faze jeste definisanje veličine bloka, odnosno rastera, jednoporodičnog stanovanja. Određena je proizvoljna veličina bloka dimenzija $1000 \mathrm{~m}$ x 1000m, što čini $10 \times 10$ stambenih jedinica definisanih $u$ prethodnom koraku. 


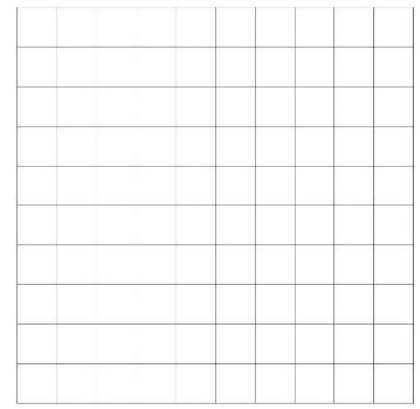

Slika 4. Veličina bloka (rastera)

Za potrebe trećeg koraka, odnosno za određivanje gustine naselja i dispozicije objekata, korišćen je ćelijski automat po uzoru na „Game of Life“. Gustina je određena izrazom:

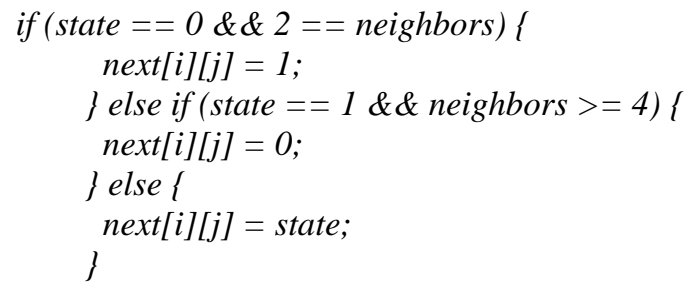

Za potrebe dinamične dispozicije stambenih jedinica, algoritam razlikuje četiri tipa izgrađenog prostora, odnosno četiri orijentacije objekta koje raspoređuje slučajnim odabirom (random), slika 5.
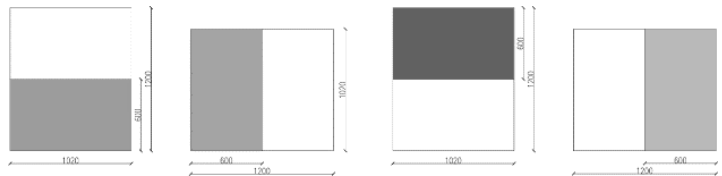

Slika 5. Četiri orijentacije objekta na parceli (četiri tipa ćelije)

Nakon određivanja veličine i gustine stambenog bloka, odnosno određivanje ćelije, algoritam generiše varijacije dispozicija stambenih jedinica po definisanim pravilnostima. Za potrebe ovog istraživanja odabrano je deset varijacija paterna stambenog bloka, slika 6 .
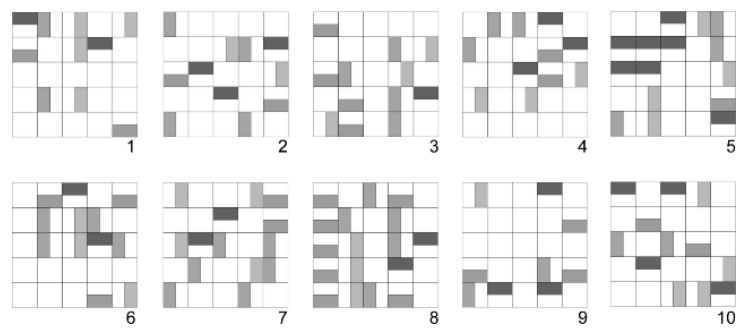

Slika 6. 10 varijacija paterna stambenog bloka

\subsection{Energetska analiza}

Kao kriterijum za odabir finalne dispozicije korišćen je Insight plug-in za Revit, slika 7. U ovom istraživanju, Insight je primenjen $\mathrm{u}$ prvom koraku na volumene kreirane po generisanim rešenjima određenim $u$ prethodnoj fazi projekta.

$\mathrm{Na}$ kreirane volumene primenjena je energetska analiza, slika 8. U odnosu na dobijene grube procene potrošnje energije, usvojene su dve dispozicije sa minimalnom količinom potrošnje.

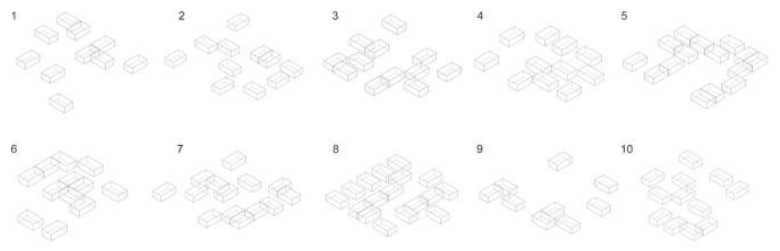

Slika 7. Modeli zadatih paterna kreirani u Revit-u
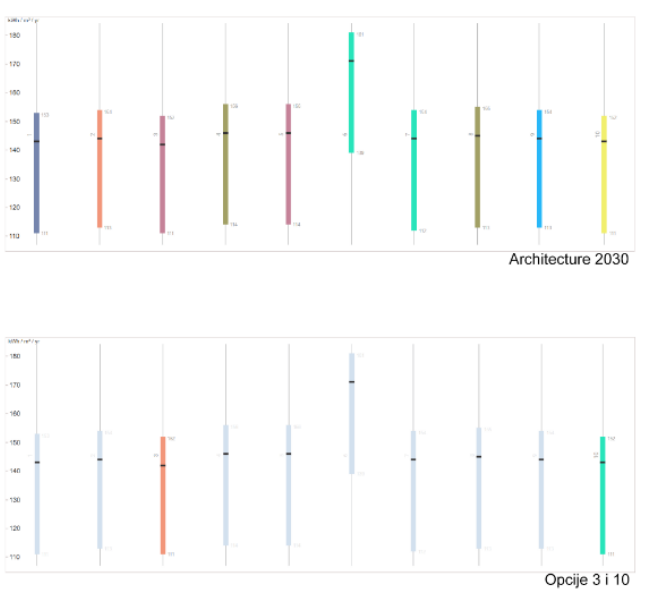

Slika 8. Energetske analize blokova dobijenih paterna

\subsection{Usvajanje paterna i finalne analize bloka}

U ovom koraku volumeni su razrađeni do nivoa materijala i mogućih otvora na fasadama. Vrši se detaljna analiza dva izabrana paterna (3 i 10) uz pomoć faktora Autodesk Insight tehnologije. U ponuđene vidžite faktora unose se potencijalni materijali po preporuci Insight-a, HVAC sistem, kao i pokrivenost krova solarnim panelima i njihova efikasnost, slika 9.
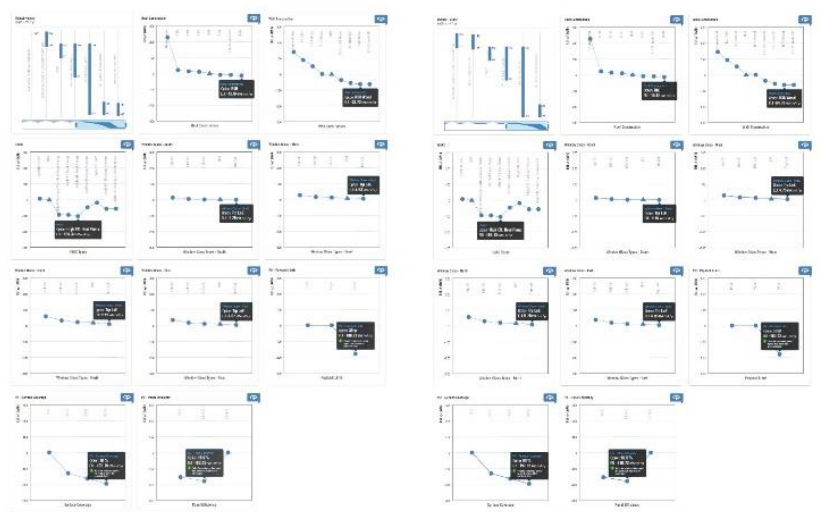

Slika 9. Vidžiti (widgets) faktora na Autodesk Insight 360

$\mathrm{Na}$ osnovu sprovedenih analiza i razmatranja, od dve najoptimalnije verzija bloka usvaja se patern broj 10, koji podržava veći broj stambenih jedinica za srazmernu energetsku potrošnju.

Dalje istraživanje usvojenog bloka sastoji se od razrade osnova i orijentacije otvora na objektima kako bi se postigla najveća osvetljenost uz maksimalnu privatnost korisnika u odnosu na susedne objekte. Kreira se radni model na kojem se vrši dalja energetska analiza, slika 10 


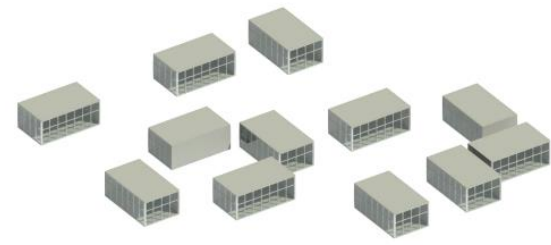

Slika 10. Radni model bloka u Revit-u

Novi model bloka rotira se za 45, 90, 135 i 180 stepeni kako bi se odredila najefikasnija pozicija, slika 11 .

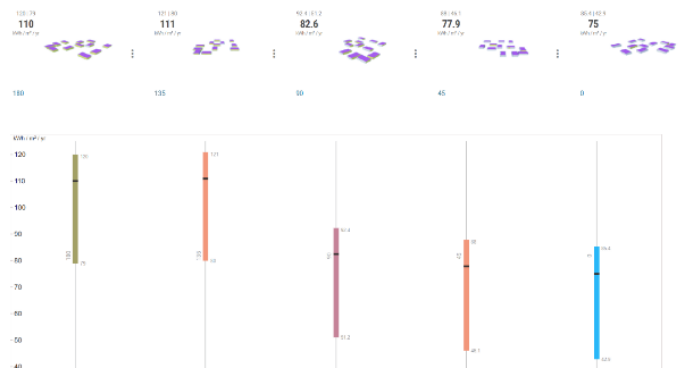

Slika 11. Energetska analiza orijentacije bloka

Energetskom analizom dolazi se do finalne verzije i orijentacije bloka. Zaključuje se da je prvenstvena odabrana orijentacija bloka energetski najefikasnija. Usvaja se finalno rešenje, slika 12. i pristupa se razradi projekta.

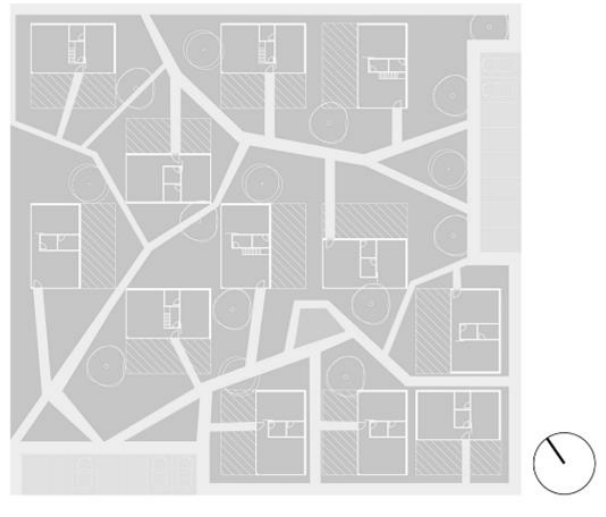

Slika 12. Usvojena orijentacija bloka

\subsection{Idejno rešenje bloka}

Zamišljena lokacija za blok je Kamenički put na Mišeluku u Novom Sadu. Orijentisan severo-zapadno, blok se nalazi pored novog objekta Televizije, slika 13.

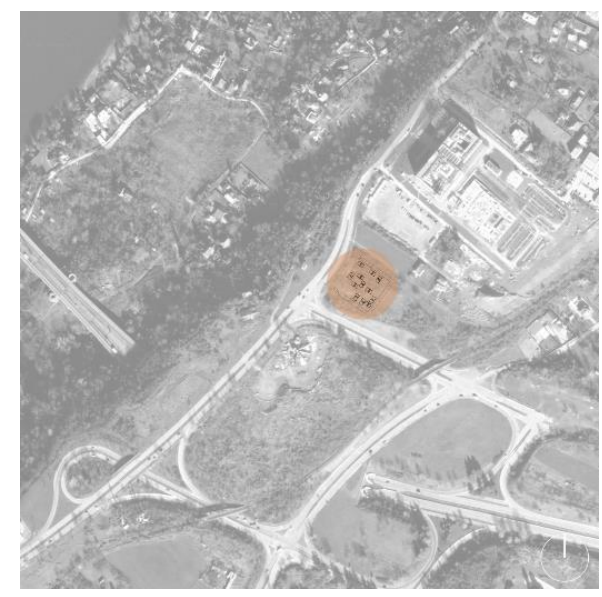

Slika 13. Situacija bloka
Idejno rešenje bloka daje primer načina na koji se može razvijati naselje. Određeni patern se može produžiti ili ponavljati, dok se stambene jedinice mogu dodavati po potrebi. Blok sačinjavaju tipske, modularne jedinice koje pružaju mogućnost projektovanja prema zahtevima i prilagođavanja potrebama korisnika. Predložena su tri verzije objekata u odnosu na njihovu spratnost, raspored i veličinu prostorija, slike 14 . i 15 ..

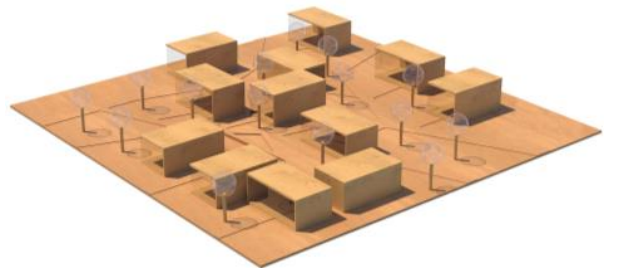

Slika 14. Maketa bloka

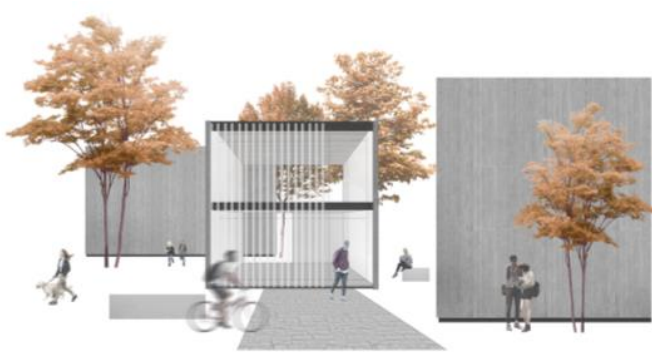

Slika 15. Vizuelizacija bloka

\section{ZAKLJUČAK}

Pritiskom na kompanije, investitore i generalnim zahtevanjem kvaliteta preko kvantiteta, kao i sopstvenim edukovanjem i istraživanjem pri kupovini, projektovanju, izgradnji i slično, možemo izazvati bitnu promenu. Inovativnim materijalima i održivim procesom izgradnje dolazi se do smanjenja negativnih uticaja, što dovodi do zaštite zdravlja, opšte dobrobiti populacije i svih živih bića.

Zahvaljujući svakodnevnim istraživanjem i razvojem novih tehnologija, kao i samoj svesti čovečanstva, ne postoji izgovor da se ne prihvate navedene izmene. Tehnologija je tu, sve što treba jeste da je upotrebimo.

\section{LITERATURA}

[1] Amany Ragheb, Hisham El-Shimy, Ghada Ragheb, "Green Architecture: A Concept of Sustainability", Urban Planning and Architecture Design for Sustainable Development, oktobar 2015.

[2] Daniel Davis, "Can Algorithms Design Buildings?", Architect Magazine, jun 2019.

[3] https://plato.stanford.edu/entries/cellular-automata/

[4] Sopstveni rad „Umnožavanje zelenih površina na parceli" za predmet Optimizacione i upravljačke tehnologije u arhitektonskom projektovanju, jun 2020.

\section{Kratka biografija:}

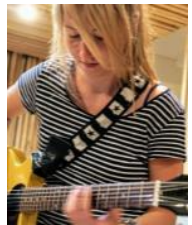

Nina Zvezdin rođena je u Novom Sadu 1993. godine. Master rad na Fakultetu tehničkih nauka iz oblasti Savremene teorije i tehnologije u arhitekturi odbranila je 2020. godine.

kontakt:nina45529@gmail.com 